\title{
Humanization and policy support: A replication-extension on group-composition framing
}

Andrej Findor ${ }^{\mathrm{a}}$, Matej Hruška ${ }^{\mathrm{a}}$, Roman Hlatky ${ }^{\mathrm{b}}$, Alexa Dvorskáa ${ }^{\mathrm{a}}$, Tomáš Hrustičc ${ }^{\mathrm{c}}$, Zuzana

$$
\text { Bošelovád, Ondrej Buchel }{ }^{\mathrm{e}}
$$

${ }^{a}$ Faculty of Social and Economic Sciences, Comenius University, Mlynské luhy 4, 82105 Bratislava, Slovak Republic

${ }^{\mathrm{b}}$ Department of Government, The University of Texas at Austin, $158 \mathrm{~W} 21$ st ST STOP A1800, Batts Hall 2.116, Austin, TX 78712-1704, United States of America

${ }^{\mathrm{c}}$ Institute of Ethnology and Social Anthropology, Slovak Academy of Sciences, Klemensova 19, 81364 Bratislava, Slovak Republic

${ }^{d}$ Milan Šimečka Foundation, Svoradova 747/5, 81103 Bratislava, Slovak Republic

${ }^{\mathrm{e}}$ Social Policy Institute of the Ministry of Labour, Social Affairs and Family of the Slovak Republic, Špitálska 4, 81643 Bratislava, Slovak Republic

Draft date: November 30, 2021

Manuscript status: submitted for publication

\section{Author Note}

The data, replication instructions, the data's codebook, questionnaires and preregistration protocols can be found at https://osf.io/4wy2g/?view_only=eedd10f0fb1a460e8338cbb4659891eb

We have no know conflicts of interest to disclose.

Our work was funded by the European Union's Rights, Equality and Citizenship Programme (Grant No. 809869 - PERCOM). They were not involved in any stage of the research process. The content of this article represents the views of the authors only and is their sole responsibility. The European Commission does not accept any responsibility for use that may be made of the information it contains.

We would like to thank students of Social Science Research Methods class at Faculty of Social and Economic Sciences, Comenius University Bratislava and Stano Daniel from Porticus Vienna for helpful feedback.

Correspondence concerning this article should be addressed to Andrej Findor, Faculty of Social and Economic Sciences, Comenius University, Mlynské luhy 4, 82105 Bratislava, Slovak Republic. Email: andrej.findor@fses.uniba.sk 


\begin{abstract}
Evaluations of beneficiary groups matter for individual levels of policy support. A variety of cues and heuristics shape evaluations. One particularly consequential heuristic concerns the beneficiary's perceived level of humanity. Recent work shows that individuals, individuals within groups (group compositions), and unitary groups evoke different levels of perceived humanity, and that these differences have downstream effects on sympathy and willingness to help. We replicate these findings, and then extend them to government policy support. We find that individuals and group compositions evoke higher levels of support than groups, and that perceived humanity explains this effect. We focus on the Roma, a tough, critical test given pervasive dehumanization and anti-Roma prejudice. Finally, we demonstrate the value of crossdisciplinary extension-replications.
\end{abstract}

Keywords: policy support, group composition, dehumanization, linguistic cues, Roma, replication, experiment 
Individual support for welfare and redistributive policies depends on how individuals perceive beneficiaries, i.e., the target group. The social construction of beneficiaries -- the normative and evaluative depictions associated with groups like need, control of circumstances, or the reciprocation of assistance -- matter for support (Bell 2021; Gilens 1999; Lawrence, Stoker, and Wolman 2013; Petersen 2012; Schneider and Ingram 1993; van Oorschot 2006). One important evaluation concerns the target group's humanity -- essential human characteristics differentiating humans from machines or animals (Zebel et al. 2008, 196-198). When beneficiaries are dehumanized, support for redistributive transfers decreases (Sainz et al. 2020). Recent work shows that subtle variations in the language used to describe target groups are consequential for how "human" a target group is perceived. Cooley et al. (2017) and a replication-extension by Hodson and Doucher (2020) show that substantive differences emerge in how people evaluate targets when they are described as either individuals, individuals within groups (group-composition), or groups. These subtle linguistic changes humanize the target -i.e., they shift individual perceptions about the extent to which the target can have experiences and agency. In turn, these changes mediate sympathy for (Cooley et al. 2017), and willingness to help the target (Hodson and Doucher 2020). ${ }^{1}$ Groups evoke the least sympathy and willingness to help, while individuals evoke the most. Yet, the linguistic shift of referencing individuals within a group leads to near-equivalent levels of sympathy and willingness to help as when individuals are mentioned. These findings have important implications for welfare policy support.

\footnotetext{
${ }^{1}$ Only changes in experience mediate willingness to help (Hodson and Doucher 2020, 1606).
} 
Thus, in this research note, we conduct a pre-registered replication and extension of Cooley et al. (2017) and Hodson and Doucher (2020). ${ }^{2}$ We make three contributions to political science literature. First, we show that linguistic shifts, through humanization, translate to differences in welfare policy support. Simply referring to beneficiaries as a collection of individuals, rather than as a unitary group, increases policy support for welfare programs. Second, we conduct the replication-extension with a nationally-representative sample of Slovaks and with the Roma as the target group. The substantive differences between samples (the previous studies employed American MTurkers), and the Roma target group render our analysis a tough test of external validity. Importantly, given the discrimination and prejudice against the Roma (Kende et al. 2020) and their blatant dehumanization (Kteily et al. 2015), the fact that variations in language improve welfare policy support means that these effects will likely manifest for other, less stigmatized groups as well. In other words, the Roma are a tough test, and we consider our findings a floor. Finally, this analysis contributes to the growing calls for, and shows the value of, replication-extensions across disciplines.

\section{Explaining Welfare Policy Support}

The political science literature explains support for redistributive welfare policies through groupcentric models where individuals evaluate policies based on whom they perceive said policies to benefit, and evaluations associated with this beneficiary group (Schneider and Ingram 1993). Cues and heuristics inform individual evaluations. Examples include perceptions of a group's political power, deservingness (often further broken down into categories like need, control, and

${ }^{2}$ Anonymized pre-registration: https://aspredicted.org/COS_RQG (Study 1), https://aspredicted.org/ANS XBG (Study 2) 
reciprocity) (see Petersen 2012; van Oorschot 2006), or race, ethnicity, and immigration status (Gilens 1999; Soroka et al. 2016). Humanization -- the extent to which a group possesses "human" characteristics differentiating it from machines or animals -- also matters. The more "human" a target group is perceived to be, the higher the support for welfare transfers to said group (Sainz et al. 2020).

Ultimately, however, all of these explanations are predicated on beneficiaries being described as unitary groups -- e.g., the elderly (Lawrence et al. 2013) or low-income students (Bell 2021). Yet, beneficiaries can be described as individuals, or as individuals within a group (group composition). Cooley et al. (2017) and the associated replication by Hodson and Doucher (2020) show that these subtle linguistic differences have stark implications for the level of humanity individuals attribute to the target, and that these shifts have downstream consequences for sympathy towards and willingness to help the target group.

Specifically, individuals react differently to these labels because shifts from individual, to group composition, to group evoke different perceptions of the target's capacity to experience (to sense and feel) and to have agency (to intentionally think and act), core elements of "humaneness". Groups score lower than individuals or group compositions on these outcomes. Yet, respondents judge individuals and group compositions almost equivalently. Cooley et al. show that shifts in experience and agency mediate respondents' sympathy for the target, and Hodson and Doucher show that shifts in capacity to experience mediate the extent to which an individual is willing to help the target. Respondents were less sympathetic towards, and less willing to help groups than individuals or people in groups.

We suggest that humanization through linguistic labels affects the level of policy support a target evokes. Thus, in our extension, we test whether individual support for welfare transfers 
to individuals, group compositions, or groups differs, and whether humanization mediates these changes.

\section{Study 1: Replicating Cooley et al. (2017, Study 3) and Hodson and Doucher (2020)}

Cooley et al. 2017 (Study 3) and Hodson and Doucher (2020), using between-subject designs, randomly assigned participants to three conditions. In each condition, a vignette describes a target who had the same event befall them:

- Individual: Take a moment to imagine a man who was quite successful. Now imagine that, recently, the man's electronic security firewalls were breached, and his private accounts were hacked, and as a result he went bankrupt.

- Group-Composition: Take a moment and imagine 20 employees who compose a small company and who were quite successful. Now imagine that, recently, the 20 employees' electronic security firewalls were breached, and their private accounts were hacked, and as a result the company went bankrupt.

- Group: Take a moment to imagine a small company that was quite successful. Now imagine that, recently, the company's electronic security firewalls were breached, and its private accounts were hacked, and as a result the company went bankrupt.

After reading vignettes, participants rated the target's capacity for experience (pain and suffering) and agency (intentions and goals) on 0-100 scales. ${ }^{3}$ Then participants rated their sympathy for the target (0-100). In Hodson and Doucher, participants also indicated their willingness to help the target (0-100).

To replicate these studies, we recruited a nationally representative sample of Slovaks using an online panel. While Cooley et al. recruited 242 participants from MTurk, and Hodson and Doucher recruited 500 participants from the same platform, we recruited 1014 participants $(M$ age $=44.5, S D$ age $=15.8,52 \%$ female $)$. Post-hoc analysis for global effects using G*Power

\footnotetext{
${ }^{3}$ Questionnaires available at: https://osf.io/4wy2g/?view_only=eedd10fofb 1a460e8338cbb4659891eb
} 
showed that a MANOVA with 1,014 participants across three groups would be sensitive to effects as small as $f^{2}=0.007$ with $80 \%$ power $(\alpha=.05)$.

To analyse differences in outcomes across groups, we used a resampling-based MANOVA with 1000 iterations (see Friedrich, Konietschke and Pauly 2019). To test the mediation hypotheses -- that shifts in perceptions of experience and agency explain sympathy and willingness to help -- we used the mma package for $\mathrm{R}(\mathrm{Yu}, \mathrm{Li} 2017)$ and estimated mediation models using Multiple Additive Regression Trees, a modelling method that considers nonlinear relationships. We defined experimental conditions as predictors, attributions of experience and agency as mediators, and sympathy for the target and willingness to help as outcomes. We used the default option of 50 bootstrap resamplings.

$\underline{\text { Results: }}$ Plotting the data (Figure 1) shows similar scores for the individual and groupcomposition frames, and lower scores in the group frame across all outcomes (Table 1 provides descriptive statistics). The results of the MANOVA analysis confirm an overall effect for the linguistic label manipulation on the outcome variables: $\operatorname{WTS}(8)=53.2$, resampled $p<.001$; MATS $=86.2$, resampled $p=<.001$. Multivariate post-hoc comparisons with Tukey contrasts showed a significant difference between the group and individual conditions $(p=.004$, estimated summary effect $=-19.5$ ), as well as a significant difference between group and group composition $(p<.001$, estimated summary effect $=-32.9)($ see Table 2$)$. Thus, individuals evaluated groups less favourably than individuals and group compositions.

Individual analyses of variance for each outcome variable showed a significant effect of linguistic label on experience $\left(F(2,1011)=7.87, p<.001, \omega^{2}=0.013\right)$, agency $(F(2,1011)=$ $\left.8.93, p<.001, \omega^{2}=0.015\right)$, sympathy $\left(F(2,1011)=9.53, p<.001, \omega^{2}=0.034\right)$ and willingness 
to help $\left(F(2,1011)=18.92, p<.001, \omega^{2}=0.013\right.$. Post-hoc comparisons show significant differences between the individual and group frames in all outcomes, except sympathy; and between the group-composition and group frames across all four outcomes. Further details are reported in the Supplementary Material (SM) (Tables 4-7). ${ }^{4}$

Figure 1: Distributions, means, and 95\% confidence intervals of outcomes across experimental conditions.
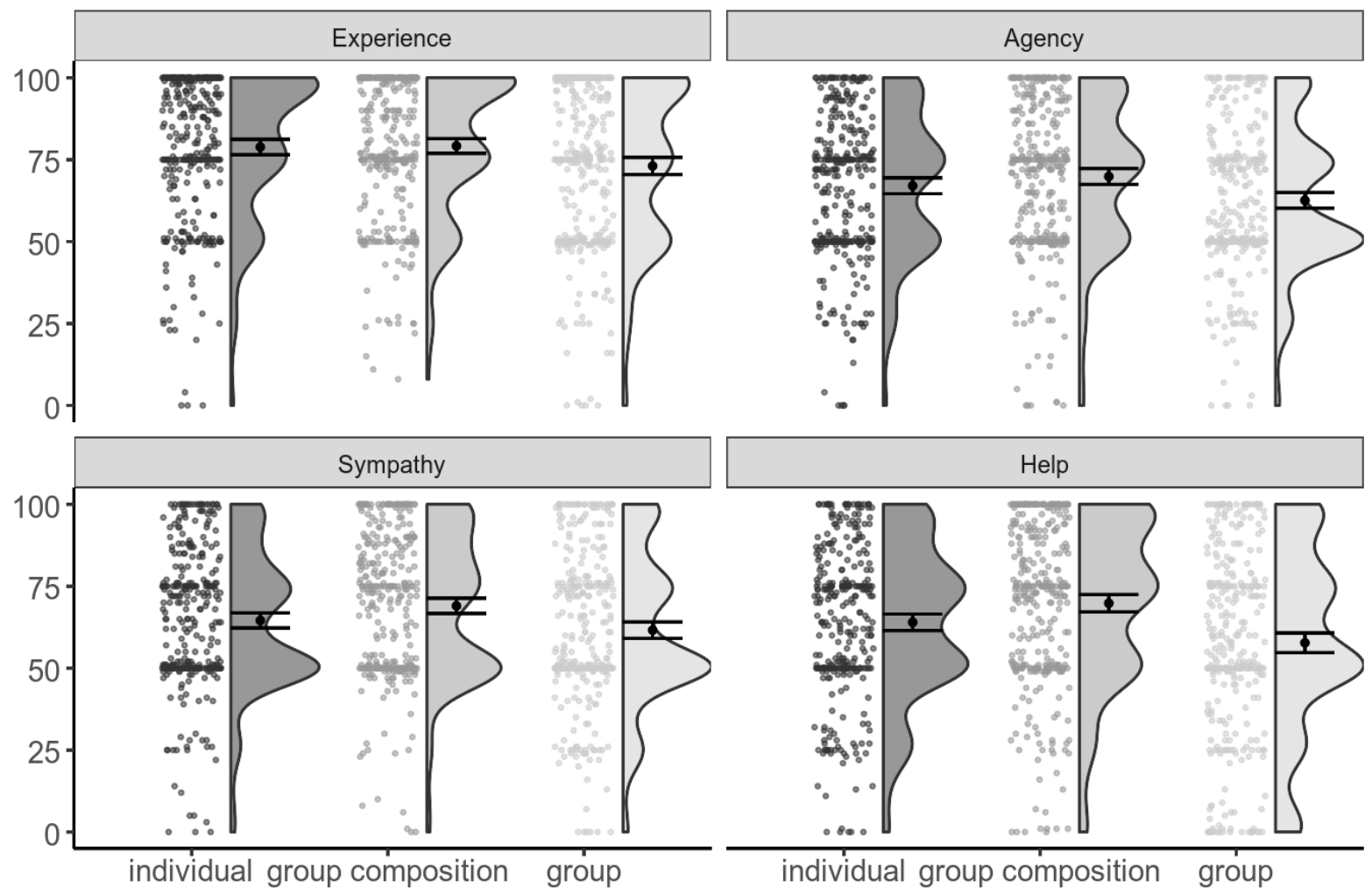

\footnotetext{
${ }^{4}$ We re-estimate analyses excluding manipulation check failures. Results remain largely consistent. Post-hoc differences between individual and group summary effects become non-significant $(\mathrm{p}=0.107)$, and univariate comparisons show nonsignificant effects of target-group condition for experience or agency. Full results in SM, Tables 3-7.
} 
Table 1: Study 1 descriptive statistics across outcomes and experimental groups

\begin{tabular}{|c|c|c|c|c|}
\hline & $M$ & $S D$ & CI & $\mathrm{N}$ \\
\hline \multicolumn{5}{|l|}{ Experience } \\
\hline individual & 78.9 & 21.9 & 2.35 & 337 \\
\hline composition & 79.2 & 21.1 & 2.25 & 340 \\
\hline group & 73.1 & 24.4 & 2.61 & 337 \\
\hline \multicolumn{5}{|l|}{ Agency } \\
\hline individual & 67 & 22.6 & 2.42 & 337 \\
\hline composition & 69.9 & 22.8 & 2.43 & 340 \\
\hline group & 62.6 & 22.5 & 2.41 & 337 \\
\hline \multicolumn{5}{|l|}{ Sympathy } \\
\hline individual & 64.6 & 21.3 & 2.28 & 337 \\
\hline composition & 69 & 21.9 & 2.33 & 340 \\
\hline group & 61.6 & 23.4 & 2.51 & 337 \\
\hline \multicolumn{5}{|l|}{ Willingness to help } \\
\hline individual & 64 & 23.5 & 2.52 & 337 \\
\hline composition & 69.8 & 24.8 & 2.65 & 340 \\
\hline group & 57.8 & 28.1 & 3.01 & 337 \\
\hline
\end{tabular}

Table 2: Differences between experimental conditions (summary effects)

\begin{tabular}{lcccc}
\hline Contrast & $\begin{array}{c}\text { Summary effect } \\
\text { estimate }\end{array}$ & $95 \%$ CI lower & 95\% CI upper & $p$ \\
\hline composition - individual & 13.4 & -0.58 & 27.41 & .064 \\
group - individual & -19.5 & -34.13 & -4.78 & .005 \\
group - composition & -32.9 & -47.62 & -18.12 & $<.001$ \\
\hline
\end{tabular}

Note: Summary effects are averaged over all dimensions, confidence intervals are based on the bootstrap version of the sum statistic, confidence intervals and $p$ values maintain a given level of alpha. 
For mediation analysis, we create two contrasts. First, we combine the group and groupcomposition conditions and compare to the individual condition; second, we compare the group condition to the group-composition condition. Table 3 presents these results. For sympathy, we find no significant effects in the combined group versus individual conditions. However, shifting from group to group-composition frame had a direct effect on sympathy, as well as indirect effects through agency, but not experience. In other words, respondents who read the company vignette reported less sympathy for the target compared to those who read the vignette about 20 people in a company, and this effect can partially be explained by changes in individual perceptions of the target's ability to have agency. Finally, the group versus group-composition manipulation had significant direct and indirect effects on willingness to help. Opposite to Hodson and Doucher, however, the manipulation had an indirect effect through agency, not experience. Also, unlike Cooley et al. and Hodson and Doucher, we find a direct effect for the group versus group-composition manipulation. 
Table 3: Direct and Indirect Effects of Experimental Conditions on Sympathy and Willingness to Help

\begin{tabular}{|c|c|c|c|c|c|c|c|c|}
\hline & \multicolumn{2}{|c|}{ Total effect } & \multirow{2}{*}{\multicolumn{2}{|c|}{ Direct effect }} & \multicolumn{4}{|c|}{ Indirect effects } \\
\hline & \multirow[b]{2}{*}{$\begin{array}{l}\text { avg. } \\
\text { est. }\end{array}$} & \multirow[b]{2}{*}{$\begin{array}{c}95 \% \text { CI } \\
\text { (c.b.) }\end{array}$} & & & \multicolumn{2}{|c|}{ experience } & \multicolumn{2}{|r|}{ agency } \\
\hline & & & $\begin{array}{l}\text { avg. } \\
\text { est. }\end{array}$ & $\begin{array}{l}95 \% \text { CI } \\
\text { (c.b.) }\end{array}$ & $\begin{array}{l}\text { avg. } \\
\text { est. }\end{array}$ & $\begin{array}{l}95 \% \mathrm{CI} \\
\text { (c.b.) }\end{array}$ & $\begin{array}{l}\text { avg. } \\
\text { est. }\end{array}$ & $\begin{array}{l}95 \% \mathrm{CI} \\
\text { (c.b.) }\end{array}$ \\
\hline \multicolumn{9}{|l|}{ Sympathy } \\
\hline $\begin{array}{l}\text { combined group } \\
\text { vs individual }\end{array}$ & \multicolumn{2}{|c|}{$-0.12(-1.96,1)$} & \multicolumn{2}{|c|}{$0.76(-0.01,1.48)$} & \multicolumn{2}{|c|}{$-0.72(-1.37,0.04)$} & \multicolumn{2}{|c|}{$-0.19(-0.84,0.54)$} \\
\hline $\begin{array}{r}\text { group vs group- } \\
\text { composition }\end{array}$ & \multicolumn{2}{|c|}{$\mathbf{- 4 . 9 6}(-7.45,-2.68)$} & \multicolumn{2}{|c|}{$\mathbf{- 2 . 2 0}(-3.99,-0.45)$} & \multicolumn{2}{|c|}{$-1.07(-2.16,0.41)$} & \multicolumn{2}{|c|}{$\mathbf{- 1 . 4 3}(-2.44,-0.35)$} \\
\hline \multicolumn{9}{|l|}{$\begin{array}{l}\text { Willingness to } \\
\text { help }\end{array}$} \\
\hline $\begin{array}{r}\text { combined group } \\
\text { vs individual }\end{array}$ & \multicolumn{2}{|c|}{$-0.57(-1.63,0.97)$} & \multicolumn{2}{|c|}{$0.22(-0.89,1.81)$} & \multicolumn{2}{|c|}{$-0.6(-1.08,0.02)$} & \multicolumn{2}{|c|}{$-0.22(-0.86,0.35)$} \\
\hline $\begin{array}{l}\text { group vs group- } \\
\text { composition }\end{array}$ & \multicolumn{2}{|c|}{$-7.57(-10.62,-3.93)$} & \multicolumn{2}{|c|}{$\mathbf{- 5 . 6 8}(-8.28,-1.65)$} & \multicolumn{2}{|c|}{$-0.66(-1.66,0.39)$} & \multicolumn{2}{|c|}{$\mathbf{- 1 . 2 7}(-2.12,-0.38)$} \\
\hline
\end{tabular}

Note: avg.est. $=$ average estimated effect from bootstrap samples; $95 \% \mathrm{CI}=$ confidence ball bounds based on bootstrap estimates. Mediation effect is the rate of change in outcome. Due to potential correlation between mediators and overlapping mediation effects, the sum of direct and indirect effects may not equal the total effects. (Yu and Li 2017; Yu and Li 2021). Bolded coefficients represent $\mathrm{p}<0.05$.

Taken together, these results largely support the findings of Cooley et al. and Hodson and Doucher. We confirm that group composition and individual target groups evoke similar levels of sympathy and willingness to help, and that these levels are higher than those evoked by groups. In the case of sympathy, we also confirm that agency is a significant mediator in the group versus group composition comparison. Finally, our results differ slightly from Hodson and Doucher, as the effect of group versus group composition on willingness to help is mediated by agency, and not experience.

\section{Study 2: Extension to Policy Support}


We predict that increases in agency and experience associated with the individual and group-composition labels (compared to the group label) will translate to increased levels of policy support. The shift away from the group humanizes the target. In turn, humanization increases policy support.

To test, we rerun Study 1 with two changes: (1) the vignettes focus on a minority outgroup in Slovakia, the Roma; and (2) we add policy support as an outcome measure, asking respondents to what extent they support a government financial transfer policy aiding the mentioned beneficiary (0-100). We rewrote the vignettes as follows:

- Individual: Take a moment to imagine a man who lives in a marginalized Roma community. Now imagine that, recently, the man lost his housing. A landslide destroyed his home, and ensured that the man was left without a roof over his head.

- Group-Composition: Take a moment to imagine twenty people who live in a marginalized Roma community. Now imagine that, recently, these twenty people lost their housing. A landslide destroyed their homes, and ensured that these twenty people were left without a roof over their heads.

- Group: Take a moment to imagine a marginalized Roma community. Now imagine that, recently, this community lost their housing. A landslide destroyed their homes, and ensured that this community was left without a roof over their heads.

As in Study 1, we recruited a representative (to the Slovak population) sample of 1,008 participants from an online panel $(M$ age $=44.3, S D$ age $=15.7,52 \%$ female $)$. Respondents who participated in Study 1 were not eligible. A post-hoc analysis for global effects using G*Power showed that a MANOVA with 1,008 participants across three groups would be sensitive to effects as small as $f^{2}=0.008$, with $80 \%$ power $(\alpha=.05)$.

Results: We begin by plotting the data (Figure 2). The individual condition consistently scored the highest, while the group condition scored the lowest. Generally, the group-composition 
condition fell somewhere between the two. Importantly, the group condition evoked significantly lower evaluations than the other two conditions across the outcomes. Table 4 presents descriptive statistics.

Figure 2. Distributions, means and 95\% confidence interval of outcomes in respective conditions.
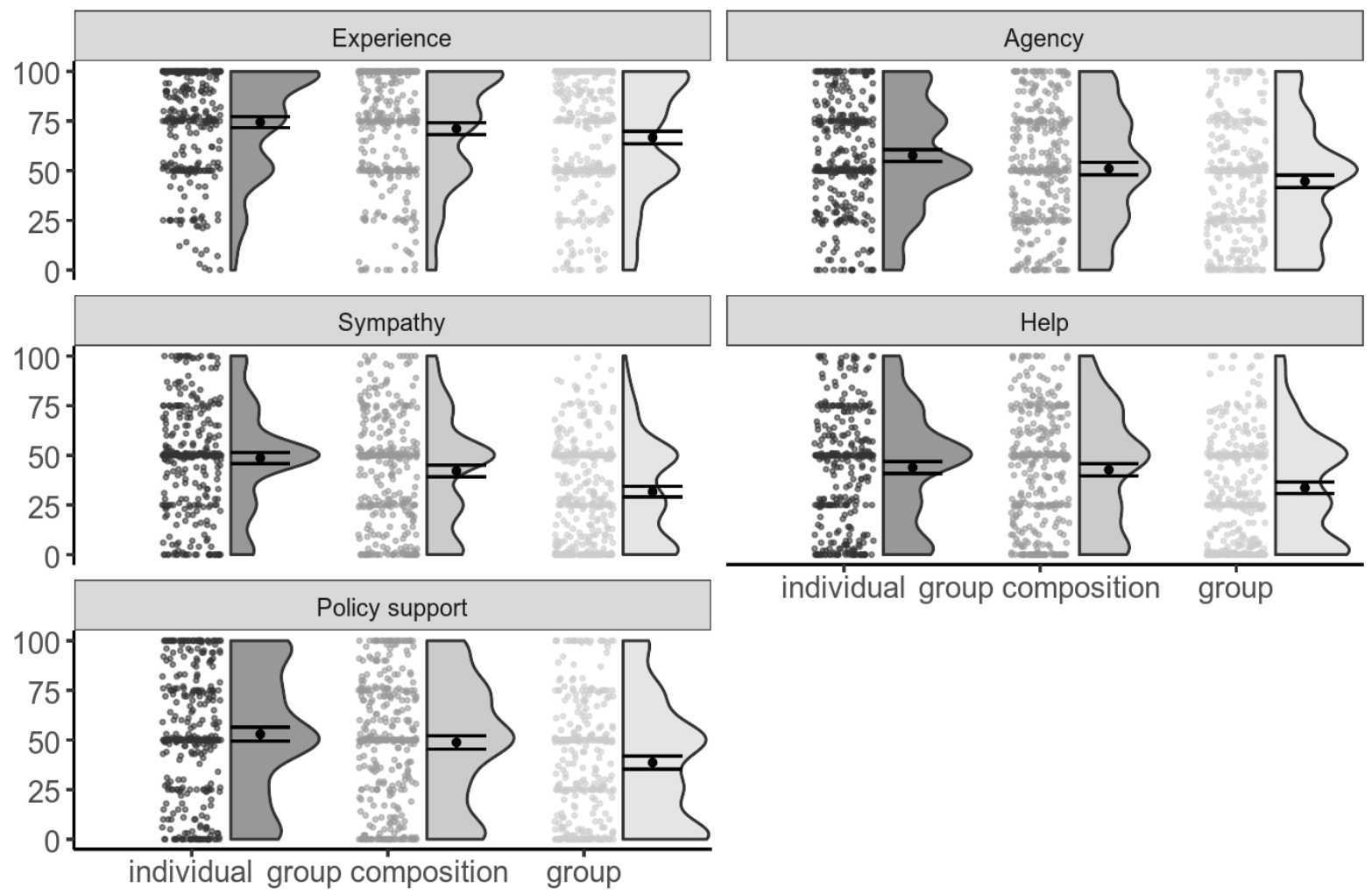
Table 4: Study 2 descriptive statistics across outcomes and experimental groups

\begin{tabular}{|c|c|c|c|c|}
\hline & $M$ & $S D$ & $\mathrm{CI}$ & $\mathrm{N}$ \\
\hline \multicolumn{5}{|l|}{ Experience } \\
\hline individual & 74.4 & 26.1 & 2.81 & 334 \\
\hline composition & 71.2 & 28.1 & 3.01 & 337 \\
\hline group & 66.7 & 29.5 & 3.16 & 337 \\
\hline \multicolumn{5}{|l|}{ Agency } \\
\hline individual & 57.6 & 27.7 & 2.98 & 334 \\
\hline composition & 51 & 29.5 & 3.17 & 337 \\
\hline group & 44.7 & 29.3 & 3.14 & 337 \\
\hline \multicolumn{5}{|l|}{ Sympathy } \\
\hline individual & 48.6 & 25.9 & 2.79 & 334 \\
\hline composition & 42.1 & 27.5 & 2.94 & 337 \\
\hline group & 31.7 & 25.2 & 2.7 & 337 \\
\hline \multicolumn{5}{|l|}{ Willingness to help } \\
\hline individual & 43.9 & 28.3 & 3.04 & 334 \\
\hline composition & 42.7 & 29 & 3.1 & 337 \\
\hline group & 33.7 & 27.1 & 2.9 & 337 \\
\hline \multicolumn{5}{|l|}{ Policy support } \\
\hline individual & 52.9 & 32.6 & 3.51 & 334 \\
\hline composition & 48.8 & 31.2 & 3.35 & 337 \\
\hline group & 38.6 & 30.9 & 3.31 & 337 \\
\hline
\end{tabular}

More formally, we estimated the overall effects of experimental conditions across all five outcome variables using the same process as in Study 1 (results in Table 5). There was a significant effect of linguistic label on all outcome variables: WTS $(10)=85.25$, resampled $p<$ $.001 ;$ MATS $=187$, resampled $p=<.001$. Multivariate post-hoc comparisons with Tukey contrasts showed a significant difference between the group and individual conditions $(p=$ $<.001$, estimated summary effect $=-62.1)$, as well as a difference between the group and group 
composition conditions $(p<.001$, estimated summary effect $=-40.4)$. Again, individuals

evaluate groups less positively than either individuals or group compositions ${ }^{5}$.

Individual analyses of variance for each outcome variable showed a significant effect of target group condition on experience $\left(F(2,1005)=6.46, p=.002, \omega^{2}=0.011\right)$, agency $(F(2$, $\left.1005)=16.96, p<.001, \omega^{2}=0.031\right)$, sympathy $\left(F(2,1005)=35.51, p<.001, \omega^{2}=0.064\right)$, willingness to help $\left(F(2,1005)=13.27, p<.001, \omega^{2}=0.024\right)$ and policy support $(F(2,1005)=$ 18.24, $\left.p<.001, \omega^{2}=0.033\right)$. The shift from individual to group led to significant post-hoc differences between all five outcomes, and the shift from group-composition to group led to significant differences in all outcomes except experience. Finally, there was a significant difference between individual and group-composition frames for agency and sympathy. For further details see SM (Tables 11-14).

Table 5: Differences between experimental conditions (summary effects)

\begin{tabular}{lcccc}
\hline & $\begin{array}{c}\text { Summary } \\
\text { effect } \\
\text { estimate }\end{array}$ & $95 \%$ CI lower & 95\% CI upper & $p$ \\
\hline contrast & -21.7 & -46 & 2.64 & .089 \\
group - individual & -62.1 & -86.1 & -38.06 & $<.001$ \\
group - composition & -40.4 & -64.8 & -16.08 & $<.001$ \\
\hline
\end{tabular}

Note: Summary effects are averaged over all dimensions, confidence intervals are based on the bootstrap version of the sum statistic, confidence intervals and $p$ values maintain a given level of alpha.

To test the mediation hypotheses, we again create two contrasts: group and group composition versus individual; and group versus group composition. Table 4 presents results. Results are consistent with previous analyses, and show that the hypothesized relationships also

${ }^{5}$ Results with manipulation check failures excluded were consistent. See SM for details (Tables 9-14). 
apply to policy support. For sympathy, we see statistically significant effects (direct and indirect) of linguistic label. The group and group-composition conditions evoked less sympathy than the individual condition, and the group condition led to less sympathy than the group-composition condition. The mediation analysis also shows that shifts in perceptions of the target group's ability to have agency explain a portion of this effect, while the mediating effect of experience was not consistent across variables and contrasts. When it comes to willingness to help and policy support, we see a similar relationship. These results suggest that the relationships evidenced in Cooley et al. and Hodson and Doucher extend to policy support. 
Table 6: Direct and Indirect Effects of Experimental Conditions on Sympathy, Willingness to Help, and Policy Support

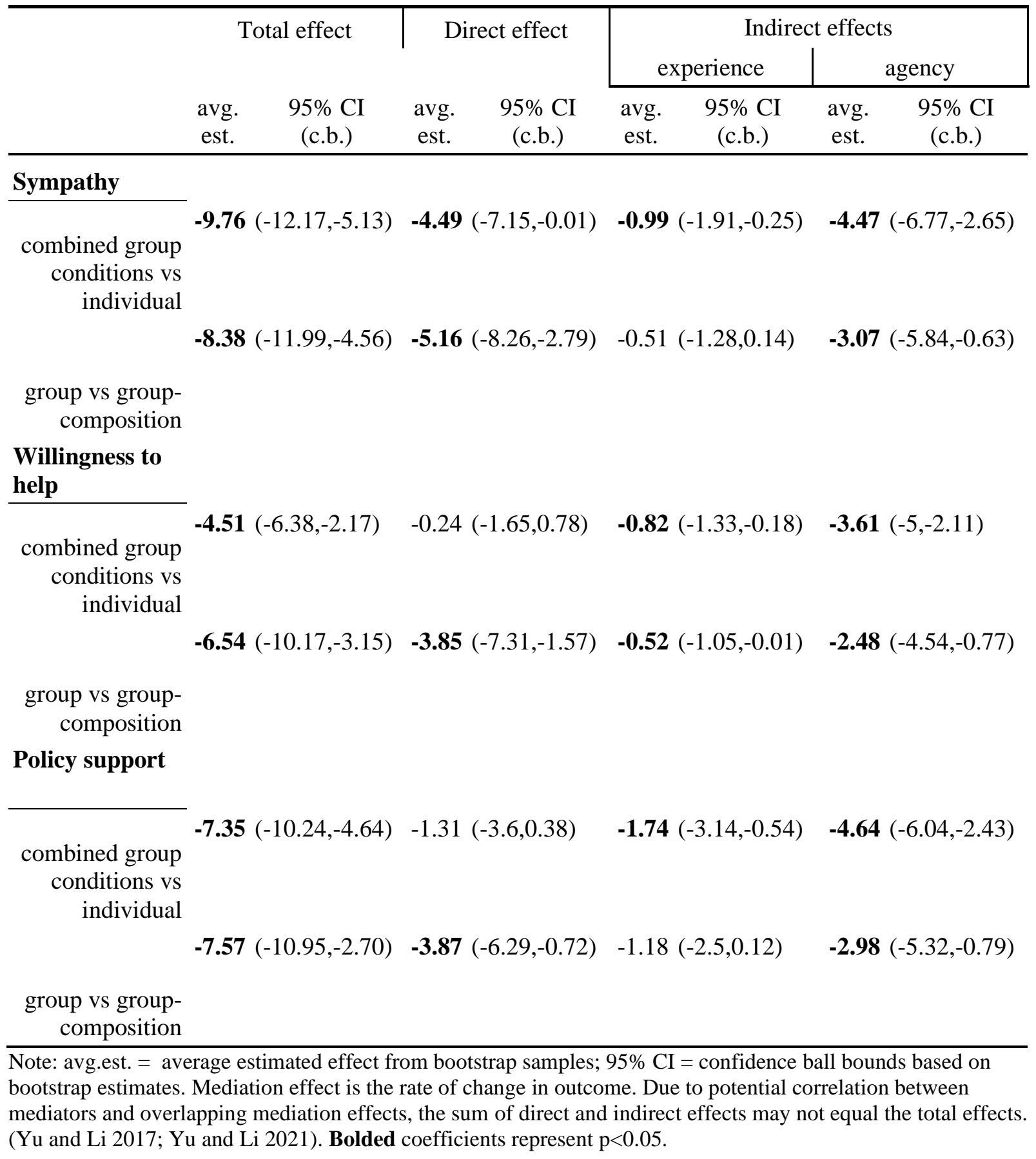




\section{Conclusion}

The language used to describe beneficiaries of redistributive transfers matters. Cues and heuristics can be overt such as when the race of a target group is mentioned; yet, as this analysis shows, subtle linguistic shifts matter as well. In our replication-extension, we first confirm the findings of Cooley et al. (2017) and Hodson and Doucher (2020): referring to beneficiaries as individuals, members of a group, or as a group evokes different levels of sympathy and willingness to help, and shifts in perceptions of experience and agency explain these changes. Second, we show that similar relationships apply to individual levels of welfare policy support. Mediation analysis unpacks the mechanisms and shows that respondents humanize group compositions to nearly the same extent as individuals. Groups score much lower in their capacity to experience or have agency. Ultimately, lower attributions of humanity translate to lower levels of policy support. Importantly, as our focus on the Roma shows, this relationship holds for stigmatized and dehumanized outgroups.

These findings offer a nuanced perspective on the study of target group dehumanization and (welfare) policy support. Even subtle forms of dehumanization, encoded in inconspicuous linguistic cues, can have considerable effects on policy support. Seeing social targets as more or less human is not only a function of stereotypes and prejudice, but also of linguistic systems, which are often used indiscriminately by individuals and institutions, no matter how positively or negatively they feel or behave towards targets. Ultimately, our findings point to linguistic sources of policy support.

These findings also have important policy implications. Funding schemes -- both at national and European levels -- are meant to benefit members of marginalized groups. For example, to promote social inclusion, the European Social Fund includes a specific Investment 
Priority (IP 9.2) about redistributive transfers to Roma communities. ${ }^{6}$ Such a policy, in its description of beneficiaries, may spur opposition and resentment amongst majorities because, paradoxically, it may dehumanize the target population it aspires to help. This work offers one, straightforward way to mollify these adverse consequences: referring to target populations in a more humanized form as individuals within groups instead of as unitary groups.

${ }^{6}$ https://www.euromanet.eu/esi-funds/ 


\section{References}

Bell, Elizabeth. 2021. 'Deserving to Whom? Investigating Heterogeneity in the Impact of Social Constructions of Target Populations on Support for Affirmative Action'. Policy Studies Journal 49 (1): 268-99. https://doi.org/10.1111/psj.12347.

Cooley, Erin, B. Keith Payne, William Cipolli, C. Daryl Cameron, Alyssa Berger, and Kurt Gray. 2017. 'The Paradox of Group Mind: "People in a Group” Have More Mind than "a Group of People".' Journal of Experimental Psychology: General 146 (5): 691-99. https://doi.org/10.1037/xge0000293.

Friedrich, Sarah, Frank Konietschke, and Markus Pauly. 2019. 'Resampling-Based Analysis of Multivariate Data and Repeated Measures Designs with the R Package MANOVA.RM'. The R Journal 11 (2): 380-400.

Gilens, Martin. 1999. Why Americans Hate Welfare: Race, Media, and the Politics of Antipoverty Policy. Chicago, IL: University of Chicago Press.

Hodson, Gordon, and Claire Doucher. 2020. 'Language Framing Shapes Dehumanization of Groups: A Successful Replication and Extension of Cooley et al. (2017).' Journal of Experimental Psychology: General 149 (8): 1603-7. https://doi.org/10.1037/xge0000723.

Kende, Anna, Márton Hadarics, Sára Bigazzi, Mihaela Boza, Jonas R. Kunst, Nóra Anna Lantos, Barbara Lášticová, Anca Minescu, Monica Pivetti, and Ana Urbiola. 2020. ‘The Last Acceptable Prejudice in Europe? Anti-Gypsyism as the Obstacle to Roma Inclusion'. Group Processes \& Intergroup Relations, May, 136843022090770. https://doi.org/10.1177/1368430220907701.

Kteily, Nour, Emile Bruneau, Adam Waytz, and Sarah Cotterill. 2015. 'The Ascent of Man: Theoretical and Empirical Evidence for Blatant Dehumanization'. Journal of Personality 
and Social Psychology 109 (5): 901-31. https://doi.org/10.1037/pspp0000048.

Lawrence, Eric, Robert Stoker, and Harold Wolman. 2013. 'The Effects of Beneficiary Targeting on Public Support for Social Policies'. Policy Studies Journal 41 (2): 199-216. https://doi.org/10.1111/psj.12014.

Oorschot, Wim van. 2006. 'Making the Difference in Social Europe: Deservingness Perceptions among Citizens of European Welfare States'. Journal of European Social Policy 16 (1): 23-42. https://doi.org/10.1177/0958928706059829.

Petersen, Michael Bang. 2012. 'Social Welfare as Small-Scale Help: Evolutionary Psychology and the Deservingness Heuristic'. American Journal of Political Science 56 (1): 1-16. https://doi.org/10.1111/j.1540-5907.2011.00545.x.

Sainz, Mario, Steve Loughnan, Rocío Martínez, Miguel Moya, and Rosa Rodríguez-Bailón. 2020. 'Dehumanization of Socioeconomically Disadvantaged Groups Decreases Support for Welfare Policies via Perceived Wastefulness'. International Review of Social Psychology 33 (1): 12. https://doi.org/10.5334/irsp.414.

Schneider, Anne, and Helen Ingram. 1993. 'Social Construction of Target Populations: Implications for Politics and Policy'. American Political Science Review 87 (2): 334-47. https://doi.org/10.2307/2939044.

Soroka, Stuart N., Richard Johnston, Anthony Kevins, Keith Banting, and Will Kymlicka. 2016. 'Migration and Welfare State Spending'. European Political Science Review 8 (2): 17394. https://doi.org/10.1017/S1755773915000041.

Yu, Qingzhao, and Bin Li. 2017. 'Mma: An R Package for Mediation Analysis with Multiple Mediators'. Journal of Open Research Software 5 (1): 11. https://doi.org/10.5334/jors.160. 
.2021. 'A Multivariate Multiple Third-Variable Effect Analysis with an Application to Explore Racial and Ethnic Disparities in Obesity'. Journal of Applied Statistics 48 (4): 750-64. https://doi.org/10.1080/02664763.2020.1738359.

Zebel, Sven, Anja Zimmermann, G. Tendayi Viki, and Bertjan Doosje. 2008. 'Dehumanization and Guilt as Distinct but Related Predictors of Support for Reparation Policies'. Political Psychology 29 (2): 193-219. https://doi.org/10.1111/j.1467-9221.2008.00623.x. 


\title{
Humanization and Policy Support: A Replication-Extension on Group-Composition
}

\author{
Framing
}

\section{SUPPLEMENTARY MATERIAL}

\author{
Tables \\ Table 1: Randomization checks, Study 1- all participants \\ Table 2: Descriptives statistics for Study 1 - manipulation check correct answers only \\ Table 3: Differences between experimental conditions (summary effects) - manipulation check \\ correct answers only \\ Table 4: Effect of target-group condition on respective outcome variables (individual ANOVAs) \\ - Study 1, all participants \\ Table 5: Post-hoc comparisons, Study 1, all participants \\ Table 6: Effect of target-group condition on respective outcome variables (individual ANOVAs) \\ - manipulation check correct answers only \\ Table 7: Post-hoc comparisons, Study 1 - manipulation check correct answers only \\ Table 8: Randomization checks, Study 2, all participants \\ Table 9: Descriptive statistic for Study 2 - manipulation check correct answers only \\ Table 10: Differences between experimental conditions (summary effects) Study 2 - \\ manipulation check correct answers only \\ Table 11: Effect of target-group condition on respective outcome variables (individual \\ ANOVAs) - Study 2, all participants \\ Table 12: Post-hoc comparisons, Study 2, all participants \\ Table 13: Effect of target-group condition on respective outcome variables (individual \\ ANOVAs), Study 2- manipulation check correct answers only \\ Table 14: Post-hoc comparisons, Study 2- manipulation check correct answers only
}

\section{Figures}

Figure 1: Overlap of distributions, means, and 95\% confidence intervals of dependent variables across experimental conditions for Study 1 - all participants

Figure 2: Overlap of distributions, means, and 95\% confidence intervals of dependent variables across experimental conditions for Study 1 - correct answers only

Figure 3: Distributions, means, and 95\% confidence intervals of dependent variables across experimental conditions for Study 1 - correct answers only

Figure 4: Overlap of distributions, means, and 95\% confidence intervals of dependent variables across experimental conditions for Study 2 - all participants

Figure 5: Overlap of distributions, means, and 95\% confidence intervals of dependent variables across experimental conditions for Study 2 - correct answers only

Figure 6: Distributions, means, and 95\% confidence intervals of dependent variables across experimental conditions for Study 2 - correct answers only 
Table 1: Randomization checks, Study 1-all participants

\begin{tabular}{rccccc}
\hline variable & $\mathrm{N}$ & $\mathrm{df}$ between & $\mathrm{df}$ within & statistic & $p$ \\
\hline gender & 1014 & 2 & 674 & 0.006 & .994 \\
age & 1014 & 2 & 674 & 0.095 & .909 \\
region & 1014 & 2 & 674 & 0.009 & .991 \\
$\begin{array}{r}\text { education } \\
\text { municipality } \\
\text { size }\end{array}$ & 1014 & 2 & 674 & 0.004 & .996 \\
\hline
\end{tabular}

Table 2: Descriptives statistics for Study 1 - manipulation check correct answers only

\begin{tabular}{|c|c|c|c|c|}
\hline & $\mathrm{N}$ & $M$ & $S D$ & $\mathrm{CI}$ \\
\hline \multicolumn{5}{|l|}{ Experience } \\
\hline individual & 297 & 80.4 & 21.3 & 2.43 \\
\hline composition & 265 & 81.5 & 19.8 & 2.39 \\
\hline group & 263 & 76.5 & 24.2 & 2.94 \\
\hline \multicolumn{5}{|l|}{ Agency } \\
\hline individual & 297 & 67.1 & 22.8 & 2.6 \\
\hline composition & 265 & 69.8 & 23.8 & 2.88 \\
\hline group & 263 & 64.1 & 23.4 & 2.85 \\
\hline \multicolumn{5}{|l|}{ Sympathy } \\
\hline individual & 297 & 64.7 & 20.9 & 2.39 \\
\hline composition & 265 & 69.2 & 22.4 & 2.71 \\
\hline group & 263 & 63.2 & 23.8 & 2.9 \\
\hline \multicolumn{5}{|l|}{ Willingness to help } \\
\hline individual & 297 & 64.6 & 23.3 & 2.66 \\
\hline composition & 265 & 70.6 & 25.3 & 3.06 \\
\hline group & 263 & 59.2 & 29.2 & 3.55 \\
\hline
\end{tabular}


Table 3: Differences between experimental conditions (summary effects) - Study 1, manipulation check correct answers only

$\mathrm{WTS}(8)=31.71$, resampled $\mathrm{p}=.001 ;$ MATS $=48.2$, resampled $p<.001$

\begin{tabular}{lcccc}
\hline Contrast & $\begin{array}{c}\text { Summary effect } \\
\text { estimate }\end{array}$ & 95\% CI lower & 95\% CI upper & $p$ \\
\hline composition - individual & 14.4 & -0.43 & 29.14 & .064 \\
group - individual & -13.8 & -29.51 & 1.86 & .107 \\
group - composition & -28.2 & -44.49 & -11.87 & $<.001$ \\
\hline
\end{tabular}

Univariate $p$-values adjusted for multiple testing using Bonferroni-correction:

Agency: .136

Experience: .108

Sympathy: .02

Willingness to help: <.001

Table 4: Effect of target-group condition on respective outcome variables (individual ANOVAs) - Study 1, all participants

\begin{tabular}{|c|c|c|c|c|c|c|}
\hline & Sum of squares & $\mathrm{df}$ & Mean square & $\mathrm{F}$ & $\omega^{2}$ & $p$ \\
\hline \multicolumn{7}{|l|}{ Experience } \\
\hline group & 7971.42 & 2 & 3985.71 & 7.868 & 0.013 & $<.001$ \\
\hline Residuals & 512125.01 & 1011 & 506.55 & & & \\
\hline \multicolumn{7}{|l|}{ Agency } \\
\hline group & 9128.15 & 2 & 4564.08 & 8.934 & 0.015 & $<.001$ \\
\hline Residuals & 516503.25 & 1011 & 510.88 & & & \\
\hline \multicolumn{7}{|l|}{ Sympathy } \\
\hline group & 9419.18 & 2 & 4709.59 & 9.533 & 0.017 & $<.001$ \\
\hline Residuals & 499454.51 & 1011 & 494.02 & & & \\
\hline \multicolumn{7}{|l|}{ Willingness to help } \\
\hline group & 24688.02 & 2 & 12344.01 & 18.916 & 0.034 & $<.001$ \\
\hline Residuals & 659754.82 & 1011 & 652.58 & & & \\
\hline
\end{tabular}


Table 5: Post-hoc comparisons, Study 1, all participants

\begin{tabular}{|c|c|c|c|c|}
\hline & mean difference & S.E. & $t$ & $p$ tukey \\
\hline \multicolumn{5}{|l|}{ Experience } \\
\hline composition & -0.30 & 1.73 & -0.17 & .983 \\
\hline individual group & 5.80 & 1.73 & 3.34 & .002 \\
\hline composition group & 6.10 & 1.73 & 3.52 & .001 \\
\hline \multicolumn{5}{|l|}{ Agency } \\
\hline $\begin{array}{ll}\text { individual } & \text { composition }\end{array}$ & -2.85 & 1.74 & -1.64 & .229 \\
\hline individual group & 4.44 & 1.74 & 2.55 & .029 \\
\hline composition group & 7.29 & 1.74 & 4.20 & $<.001$ \\
\hline \multicolumn{5}{|l|}{ Sympathy } \\
\hline individual composition & -4.44 & 1.71 & -2.60 & .026 \\
\hline individual group & 2.97 & 1.71 & 1.73 & .193 \\
\hline composition group & 7.41 & 1.71 & 4.34 & $<.001$ \\
\hline \multicolumn{5}{|l|}{ Willingness to help } \\
\hline composition & -5.82 & 1.96 & -2.96 & .009 \\
\hline individual & 6.25 & 1.97 & 3.17 & .004 \\
\hline composition group & 12.08 & 1.96 & 6.15 & $<.001$ \\
\hline
\end{tabular}

Note: $p$ values with Tukey correction for respective outcome variables. 
Table 6: Effect of target-group condition on respective outcome variables (individual ANOVAs) - manipulation check correct answers only

\begin{tabular}{|c|c|c|c|c|c|c|}
\hline & Sum of squares & $\mathrm{df}$ & Mean square & $\mathrm{F}$ & $\omega^{2}$ & $p$ \\
\hline \multicolumn{7}{|l|}{ Experience } \\
\hline group & 3768 & 2 & 1884 & 3.96 & 0.007 & .019 \\
\hline Residuals & 391218 & 822 & 476 & & & \\
\hline \multicolumn{7}{|l|}{ Agency } \\
\hline group & 4319 & 2 & 2160 & 3.97 & 0.007 & .019 \\
\hline Residuals & 447397 & 822 & 544 & & & \\
\hline \multicolumn{7}{|l|}{ Sympathy } \\
\hline group & 5143 & 2 & 2571 & 5.13 & 0.01 & .006 \\
\hline Residuals & 411582 & 822 & 501 & & & \\
\hline \multicolumn{7}{|l|}{ Willingness to help } \\
\hline group & 17208 & 2 & 8604 & 12.78 & 0.028 & $<.001$ \\
\hline Residuals & 553363 & 822 & 673 & & & \\
\hline
\end{tabular}


Table 7: Post-hoc comparisons, Study 1 - manipulation check correct answers only

\begin{tabular}{|c|c|c|c|c|c|}
\hline & & mean difference & S.E. & $t$ & $p$ tukey \\
\hline \multicolumn{2}{|l|}{ Experience } & & & & \\
\hline individual & composition & -1.15 & 1.84 & -0.62 & .807 \\
\hline individual & group & 3.93 & 1.85 & 2.13 & .085 \\
\hline composition & group & 5.08 & 1.9 & 2.68 & .021 \\
\hline \multicolumn{6}{|l|}{ Agency } \\
\hline individual & composition & -2.68 & 1.97 & -1.36 & .364 \\
\hline individual & group & 3.04 & 1.98 & 1.54 & .273 \\
\hline composition & group & 5.72 & 2.03 & 2.82 & .014 \\
\hline \multicolumn{6}{|l|}{ Sympathy } \\
\hline individual & composition & -4.49 & 1.89 & -2.37 & .047 \\
\hline individual & group & 1.48 & 1.9 & 0.78 & .713 \\
\hline composition & group & 5.97 & 1.95 & 3.07 & .006 \\
\hline \multicolumn{6}{|c|}{ Willingness to help } \\
\hline individual & composition & -6.05 & 2.19 & -2.76 & .016 \\
\hline individual & group & 5.36 & 2.2 & 2.44 & .039 \\
\hline composition & group & 11.41 & 2.26 & 5.05 & $<.001$ \\
\hline
\end{tabular}


Table 8: Randomization checks, Study 2, all participants

\begin{tabular}{rccccc}
\hline variable & $\mathrm{N}$ & df between & df within & statistic & $p$ \\
\hline gender & 1008 & 2 & 670 & 0.036 & .965 \\
age & 1008 & 2 & 670 & 0.001 & .999 \\
region & 1008 & 2 & 670 & 0.004 & .996 \\
$\begin{array}{r}\text { education } \\
\text { municipality } \\
\text { size }\end{array}$ & 1008 & 2 & 670 & 0.057 & .945 \\
\hline
\end{tabular}


Table 9: Descriptive statistic for Study 2 - manipulation check correct answers only

\begin{tabular}{|c|c|c|c|c|}
\hline & $\mathrm{N}$ & $M$ & $S D$ & $\mathrm{CI}$ \\
\hline \multicolumn{5}{|l|}{ Experience } \\
\hline individual & 292 & 76.0 & 26.1 & 3.00 \\
\hline composition & 285 & 72.5 & 28.2 & 3.29 \\
\hline group & 251 & 68.0 & 29.8 & 3.70 \\
\hline \multicolumn{5}{|l|}{ Agency } \\
\hline individual & 292 & 57.7 & 28.0 & 3.22 \\
\hline composition & 285 & 50.4 & 30.4 & 3.54 \\
\hline group & 251 & 43.2 & 29.5 & 3.67 \\
\hline \multicolumn{5}{|l|}{ Sympathy } \\
\hline$\overline{\text { individual }}$ & 292 & 48.1 & 25.7 & 2.96 \\
\hline composition & 285 & 41.3 & 28.0 & 3.27 \\
\hline group & 251 & 29.0 & 23.8 & 2.96 \\
\hline \multicolumn{5}{|l|}{ Willingness to help } \\
\hline$\overline{\text { individual }}$ & 292 & 43.0 & 28.3 & 3.26 \\
\hline composition & 285 & 41.4 & 29.6 & 3.46 \\
\hline group & 251 & 31.1 & 26.2 & 3.26 \\
\hline \multicolumn{5}{|l|}{ Policy support } \\
\hline individual & 292 & 54.0 & 33.2 & 3.83 \\
\hline composition & 285 & 48.5 & 32.4 & 3.78 \\
\hline group & 251 & 35.9 & 30.7 & 3.82 \\
\hline
\end{tabular}


Table 10: Differences between experimental conditions (summary effects) Study 2 manipulation check correct answers only

$\mathrm{WTS}(10)=93.16$, resampled $\mathrm{p}<.001 ;$ MATS $=203$, resampled $\mathrm{p}<.001$.

\begin{tabular}{lcccc}
\hline Contrast & $\begin{array}{c}\text { Summary effect } \\
\text { estimate }\end{array}$ & 95\% CI lower & 95\% CI upper & $p$ \\
\hline composition - individual & -24.7 & -53.3 & 3.91 & .107 \\
group - individual & -71.6 & -100.3 & -42.87 & $<.001$ \\
group - composition & -46.9 & -76.4 & -17.33 & .001 \\
\hline
\end{tabular}


Table 11: Effect of target-group condition on respective outcome variables (individual ANOVAs) - Study 2, all participants

\begin{tabular}{|c|c|c|c|c|c|c|}
\hline & Sum of squares & $\mathrm{df}$ & Mean square & $\mathrm{F}$ & $\omega^{2}$ & $p$ \\
\hline \multicolumn{7}{|l|}{ Experience } \\
\hline group & 10082 & 2 & 5041 & 6.46 & 0.011 & .002 \\
\hline Residuals & 784343 & 1005 & 780 & & & \\
\hline \multicolumn{7}{|l|}{ Agency } \\
\hline group & 28258 & 2 & 14129 & 16.96 & 0.031 & $<.001$ \\
\hline Residuals & 837282 & 1005 & 833 & & & \\
\hline \multicolumn{7}{|l|}{ Sympathy } \\
\hline group & 48773 & 2 & 24386 & 35.51 & 0.064 & $<.001$ \\
\hline Residuals & 690110 & 1005 & 687 & & & \\
\hline \multicolumn{7}{|l|}{ Willingness to help } \\
\hline group & 20954 & 2 & 10477 & 13.27 & 0.024 & $<.001$ \\
\hline Residuals & 793771 & 1005 & 790 & & & \\
\hline \multicolumn{7}{|l|}{ Policy support } \\
\hline group & 36429 & 2 & 18214 & 18.24 & 0.033 & $<.001$ \\
\hline Residuals & 1003638 & 1005 & 999 & & & \\
\hline
\end{tabular}


Table 12: Post-hoc comparisons, Study 2, all participants

\begin{tabular}{|c|c|c|c|c|c|}
\hline & & mean difference & S.E. & $t$ & $p$ tukey \\
\hline \multicolumn{2}{|l|}{ Experience } & & & & \\
\hline individual & composition & 3.25 & 2.16 & 1.507 & .288 \\
\hline individual & group & 7.72 & 2.16 & 3.579 & .001 \\
\hline composition & group & 4.47 & 2.15 & 2.076 & .095 \\
\hline \multicolumn{2}{|l|}{ Agency } & & & & \\
\hline individual & composition & 6.59 & 2.23 & 2.956 & .009 \\
\hline individual & group & 12.98 & 2.23 & 5.824 & $<.001$ \\
\hline composition & group & 6.39 & 2.22 & 2.875 & .012 \\
\hline \multicolumn{2}{|l|}{ Sympathy } & & & & \\
\hline individual & composition & 6.50 & 2.02 & 3.212 & .004 \\
\hline individual & group & 16.90 & 2.02 & 8.351 & $<.001$ \\
\hline composition & group & 10.40 & 2.02 & 5.151 & $<.001$ \\
\hline \multicolumn{2}{|c|}{ Willingness to help } & & & & \\
\hline individual & composition & 1.16 & 2.17 & 0.534 & .855 \\
\hline individual & group & 10.20 & 2.17 & 4.698 & $<.001$ \\
\hline composition & group & 9.04 & 2.17 & 4.173 & $<.001$ \\
\hline \multicolumn{2}{|c|}{ Policy support } & & & & \\
\hline individual & composition & 4.17 & 2.44 & 1.710 & .202 \\
\hline individual & group & 14.32 & 2.44 & 5.868 & $<.001$ \\
\hline composition & group & 10.14 & 2.43 & 4.167 & $<.001$ \\
\hline
\end{tabular}


Table 13: Effect of target-group condition on respective outcome variables (individual ANOVAs), Study 2- manipulation check correct answers only

\begin{tabular}{|c|c|c|c|c|c|c|}
\hline & Sum of squares & df & Mean square & $\mathrm{F}$ & $\omega^{2}$ & $p$ \\
\hline \multicolumn{7}{|l|}{ Experience } \\
\hline group & 8774 & 2 & 4387 & 5.6 & 0.011 & .004 \\
\hline Residuals & 645905 & 825 & 783 & & & \\
\hline \multicolumn{7}{|l|}{ Agency } \\
\hline group & 28130 & 2 & 14065 & 16.4 & 0.036 & $<.001$ \\
\hline Residuals & 706851 & 825 & 857 & & & \\
\hline \multicolumn{7}{|l|}{ Sympathy } \\
\hline group & 49910 & 2 & 24955 & 37.0 & 0.08 & $<.001$ \\
\hline Residuals & 557078 & 825 & 675 & & & \\
\hline \multicolumn{7}{|l|}{ Willingness to help } \\
\hline$\overline{\text { group }}$ & 21908 & 2 & 10954 & 13.8 & 0.03 & $<.001$ \\
\hline Residuals & 654725 & 825 & 794 & & & \\
\hline \multicolumn{7}{|l|}{ Policy support } \\
\hline group & 45844 & 2 & 22922 & 22.1 & 0.049 & $<.001$ \\
\hline Residuals & 854577 & 825 & 1036 & & & \\
\hline
\end{tabular}


Table 14: Post-hoc comparisons, Study 2- manipulation check correct answers only

\begin{tabular}{|c|c|c|c|c|c|}
\hline & & mean difference & S.E. & $t$ & $p$ tukey \\
\hline \multicolumn{6}{|l|}{ Experience } \\
\hline individual & composition & 3.58 & 2.33 & 1.54 & .275 \\
\hline individual & group & 8.06 & 2.41 & 3.35 & .002 \\
\hline composition & group & 4.48 & 2.42 & 1.85 & .154 \\
\hline \multicolumn{6}{|l|}{ Agency } \\
\hline individual & composition & 7.21 & 2.44 & 2.96 & .009 \\
\hline individual & group & 14.42 & 2.52 & 5.72 & $<.001$ \\
\hline composition & group & 7.21 & 2.53 & 2.84 & .013 \\
\hline \multicolumn{6}{|l|}{ Sympathy } \\
\hline individual & composition & 6.81 & 2.16 & 3.15 & .005 \\
\hline individual & group & 19.08 & 2.24 & 8.53 & $<.001$ \\
\hline composition & group & 12.27 & 2.25 & 5.46 & $<.001$ \\
\hline \multicolumn{6}{|c|}{ Willingness to help } \\
\hline individual & composition & 1.64 & 2.35 & 0.70 & .764 \\
\hline individual & group & 11.90 & 2.42 & 4.91 & $<.001$ \\
\hline composition & group & 10.26 & 2.44 & 4.21 & $<.001$ \\
\hline \multicolumn{6}{|c|}{ Policy support } \\
\hline individual & composition & 5.45 & 2.68 & 2.03 & .105 \\
\hline individual & group & 18.11 & 2.77 & 6.54 & $<.001$ \\
\hline composition & group & 12.66 & 2.79 & 4.54 & $<.001$ \\
\hline
\end{tabular}


Figure 1: Overlap of distributions, means, and 95\% confidence intervals of dependent variables across experimental conditions for Study 1 - all participants

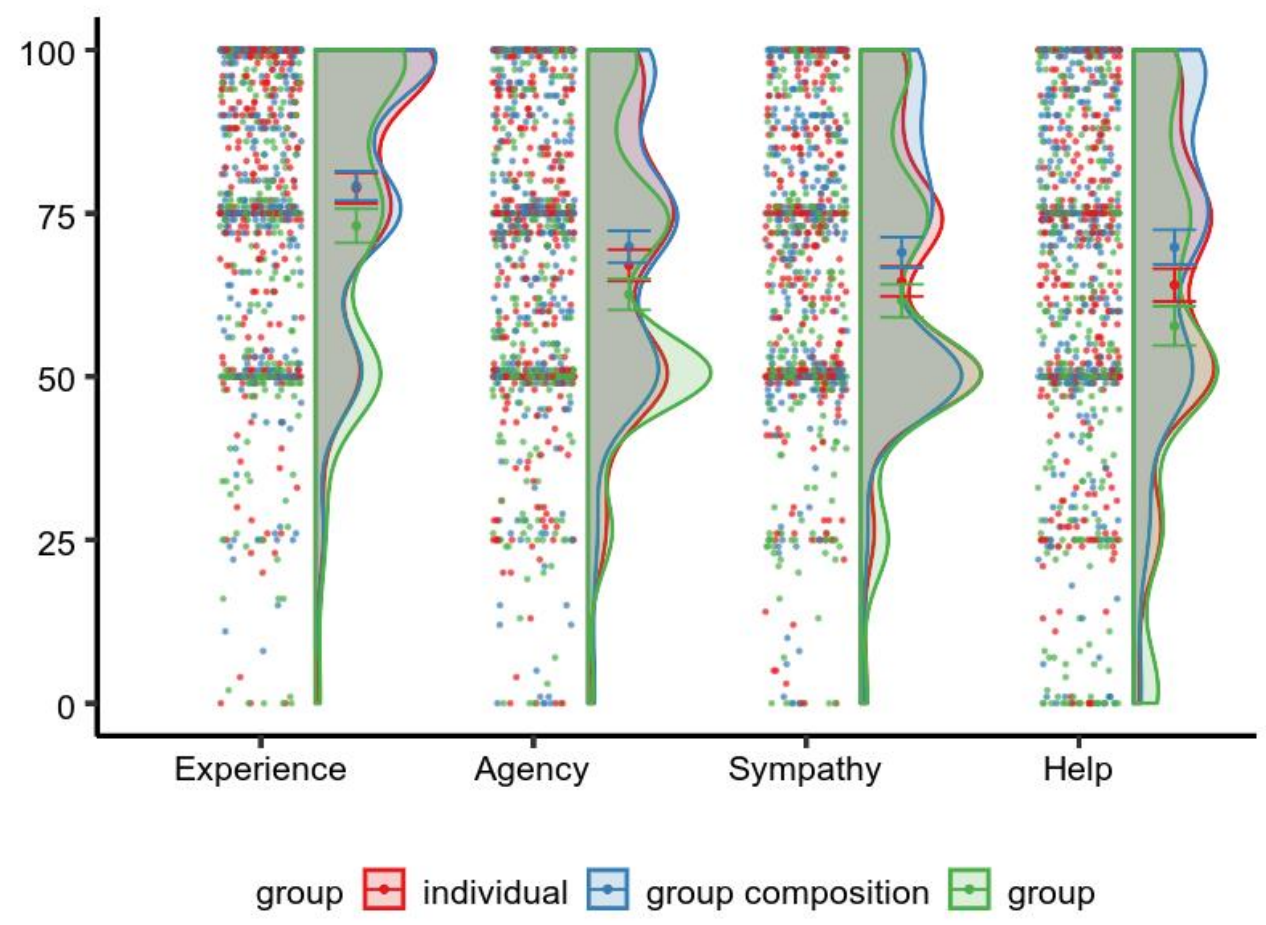

Figure 2: Overlap of distributions, means, and 95\% confidence intervals of dependent variables across experimental conditions for Study 1 - correct answers only

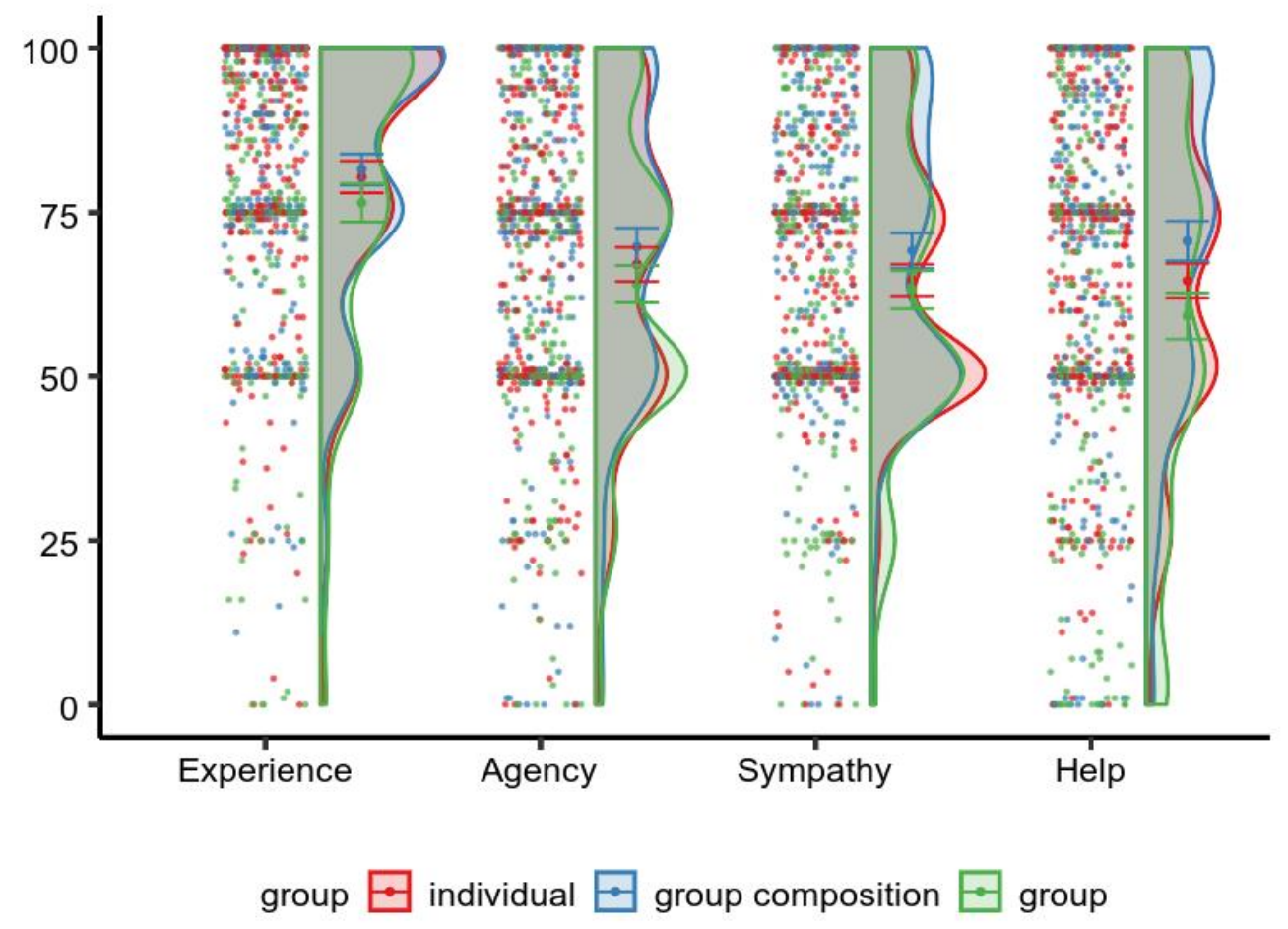


Figure 3: Distributions, means, and 95\% confidence intervals of dependent variables across experimental conditions for Study 1 - correct answers only
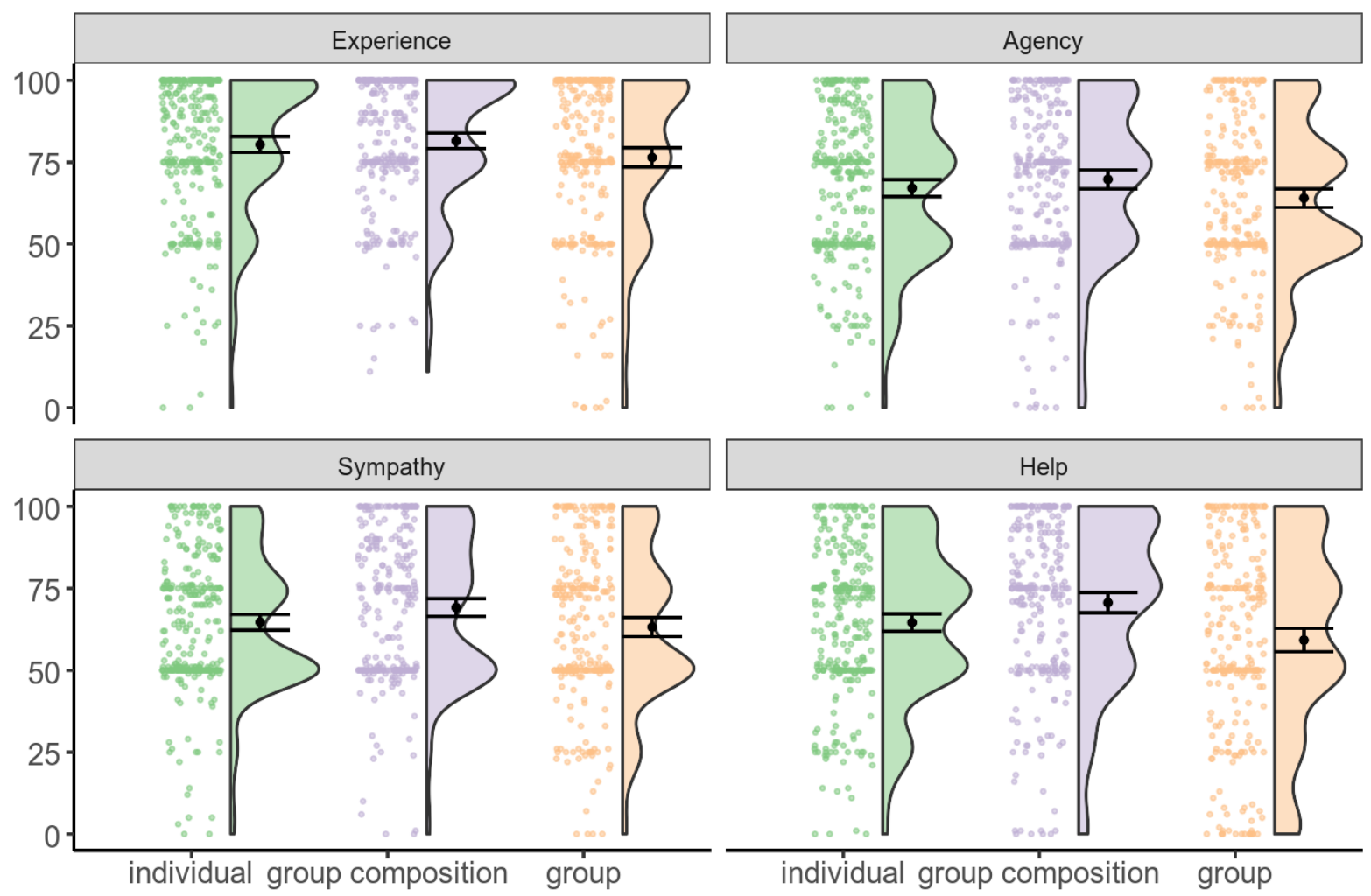
Figure 4: Overlap of distributions, means, and 95\% confidence intervals of dependent variables across experimental conditions for Study 2 - all participants

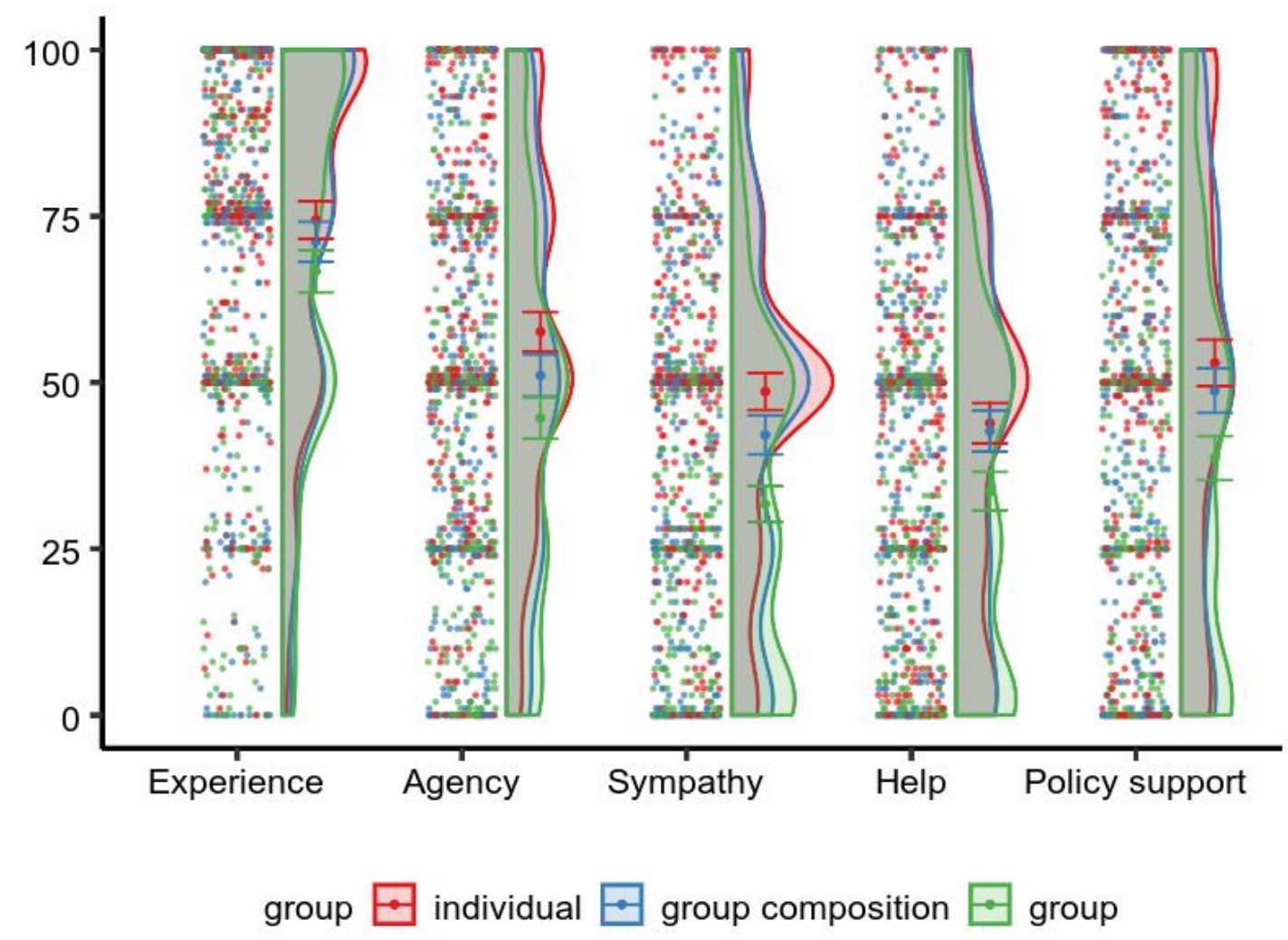


Figure 5: Overlap of distributions, means, and 95\% confidence intervals of dependent variables across experimental conditions for Study 2 - correct answers only

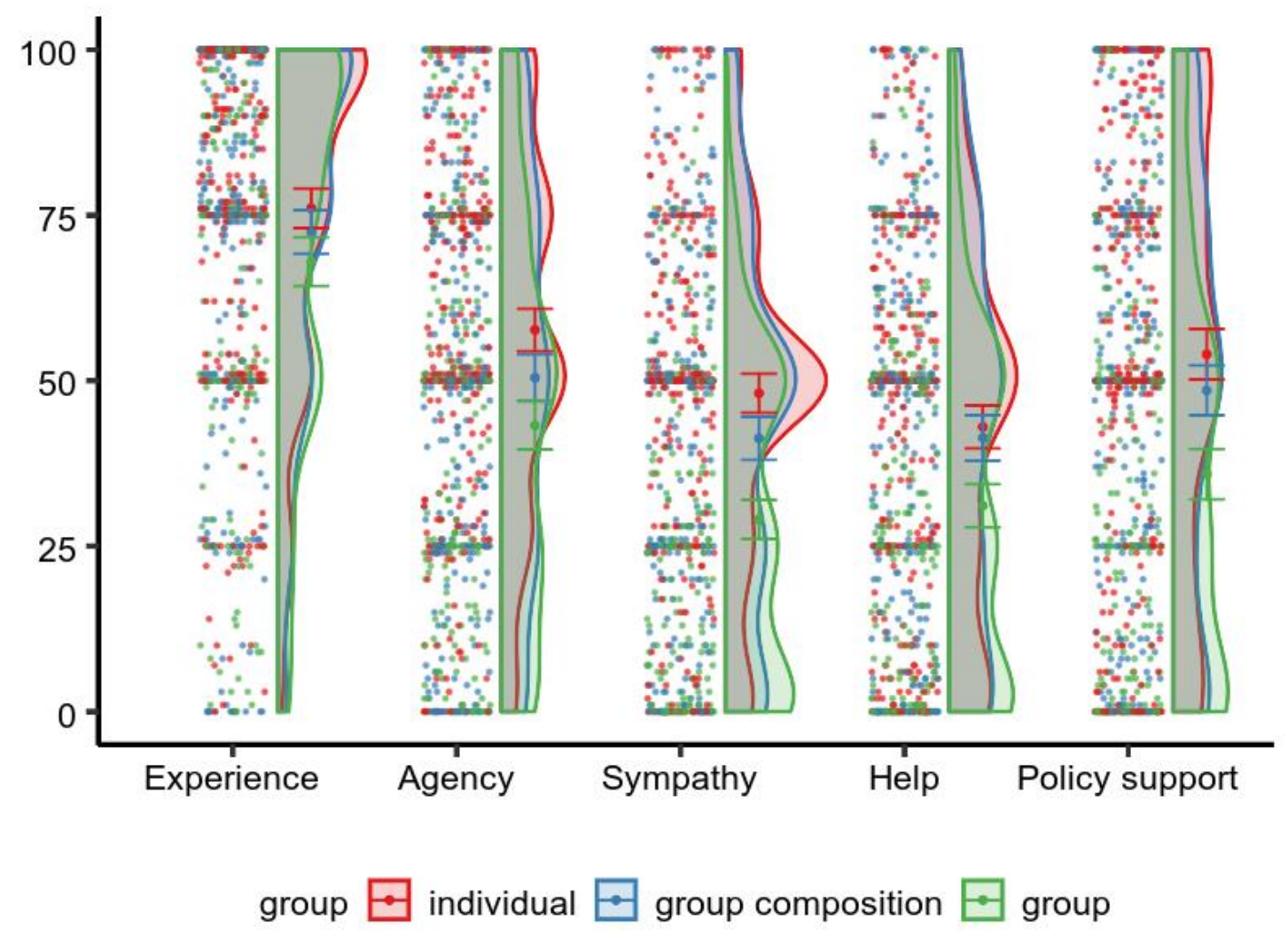


Figure 6: Distributions, means, and 95\% confidence intervals of dependent variables across experimental conditions for Study 2 - correct answers only
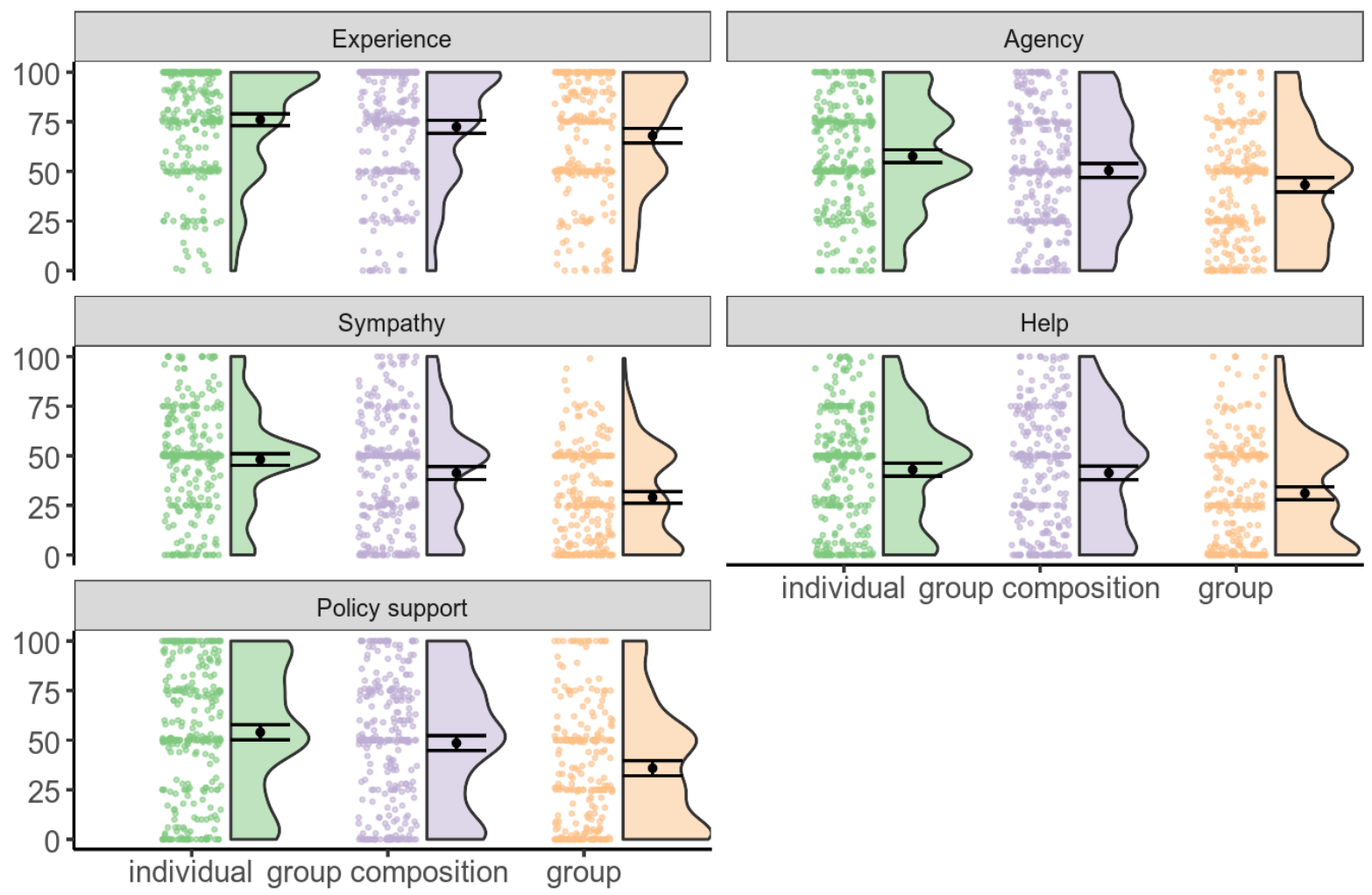